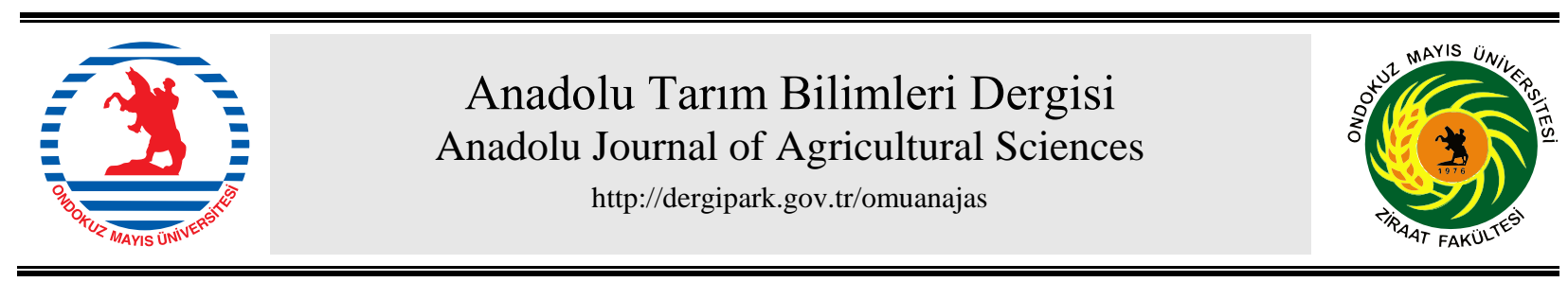

Araştırma/Research

Anadolu Tarım Bilim. Derg./Anadolu J Agr Sci, 36 (2021) ISSN: 1308-8750 (Print) 1308-8769 (Online) doi: 10.7161/omuanajas.938693

\title{
Geç olgunlaşma süresine sahip bazı tatlı sorgum (Sorghum bicolor var. saccharatum (L.) Mohlenbr.) genotiplerinin tane verimi ve biyoyakıt öğelerinin belirlenmesi
}

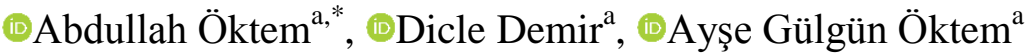

${ }^{a}$ Harran Üniversitesi, Ziraat Fakültesi, Tarla Bitkileri Bölümü, Şanlıurfa, Türkiye

*Sorumlu yazar/corresponding author: aoktem@ harran.edu.tr

Geliş/Received 19/05/2021 Kabul/Accepted 10/07/2021

ÖZET

Araştırmada geç olgunlaşma süresine sahip bazı tatlı sorgum genotiplerinin verim ve biyoyakıt ögelerinin belirlenmesi amaçlanmıştır. Deneme tesadüf blokları deneme deseninde üç tekerrürlü olarak 2019 yılı ana ürün yetiştirme sezonunda Şanlıurfa koşullarında yürütülmüştür. Çalışmada Brandes, Corina, Dale, Grassi, M81-E, P1579753, Ramada, Rio Roma, Smith, Theis, Topper 76-I, Topper 76-II, Tracy, UNL-Hybrid 3 ve Gülşeker gibi 16 adet geç olgunlaşma süresine sahip tatlı sorgum genotip'i kullanılmıştır. Çalışmada salkım çıkarma süresi, fizyolojik olgunlaşma süresi, sap verimi, tane verimi, bin tane ağırlığı ve hektolitre ağırlığı gibi özellikler incelenmiştir. Ayrıca özsu verimi, suda çözünür kuru madde oranı (brix), özsu oranı, şurup verimi, şeker verimi ve etanol verimi gibi biyoyakıt ögeleri de araştırılmıştır. Araştırma sonuçlarına göre, sap verimi 5763.3 ile $14433.2 \mathrm{~kg} \mathrm{da}^{-1}$, özsu verimi 2341.07 ile $6149.14 \mathrm{~L} \mathrm{da}^{-1}$, suda çözünür kuru madde oranı (brix) \% 13.36 ile \% 20.40 arasında ve tane verimi 82.97 ile $328.18 \mathrm{~kg} \mathrm{da}^{-1}$ arasında değişmiştir. Çalışmada salkım çıkarma süresi 72.3 ile 102.3 gün, fizyolojik olgunlaşma süresi 128 ile 168 gün, bin tane ağırlığı 15.41 ile $45.13 \mathrm{~g}$ ve hektolitre ağırlığı ise 51 ile $70 \mathrm{~kg} \mathrm{hL}^{-1}$ arasında değişmiştir. Araştırmada, özsu oranı \% 30.42 ile \% 50.37 arasında, şurup verimi 409.0 ile $931.7 \mathrm{~L} \mathrm{da}^{-1}$ arasında, şeker verimi 347.7 ile $792.0 \mathrm{~kg} \mathrm{da}^{-1}$ arasında, etanol verimi 185.1 ile $421.6 \mathrm{~L} \mathrm{da}^{-1}$ arasında değişmiştir. Sap verimi, özsu verimi, brix, şeker verimi ve biyoetanol verimi gibi biyoyakıt öğeleri göz önüne alındığında Theis, M81-E, Dale, Smith, Tracy ve UNL-Hybrid-3 gibi tatlı sorgum çeşitlerinin diğer çeşitlere göre daha verimli oldukları gözlenmiştir.

Determination of grain yield and biofuel characteristics of some late maturated sweet sorghum (Sorghum bicolor var. saccharatum (L.) Mohlenbr.) genotypes title

\section{ABSTRACT}

In the research, it was aimed to determine the yield and biofuel components of some late maturated sweet sorghum genotypes. The experiment was conducted in a randomized block design with three replications in the 2019 main crop growing season under Şanlıurfa conditions. In the study, 16 latematurated sweet sorghum genotypes such as Brandes, Corina, Dale, Grassi, M81-E, P1579753, Ramada, Rio Roma, Smith, Theis, Topper 76-I, Topper 76-II, Tracy, UNL-Hybrid-3 and Gülşeker were used. In the research, duration of panicle formation, duration of physiological maturation, stalk yield, grain yield, thousand kernel weight and hectoliter properties were investigated. In addition, biofuel components such as plant juice yield, water-soluble dry matter ratio (brix), juice ratio, syrup yield, sugar yield and ethanol yield were also investigated. Stalk yield varied between 5763.3 and $14433.2 \mathrm{~kg}$ $\mathrm{da}^{-1}$, plant juice yield between 2341.07 and $6149.14 \mathrm{~L} \mathrm{da}^{-1}$, and water-soluble dry matter ratio (brix) between $13.36 \%$ and $20.40 \%$, grain yield between 82.97 and $328.18 \mathrm{~kg} \mathrm{da}^{-1}$. In the study, the duration of panicle formation varied from 72.3 to 102.3 days, duration of physiological maturation from 128 to
Anahtar Sözcükler: Biyoetanol Brix Özsu verimi Şeker verimi Sap verimi Tatli sorgum 
168 days, thousand-grain weight from 15.41 to $45.13 \mathrm{~g}$ and hectoliter weight varied from 51 to $70 \mathrm{~kg}$ $\mathrm{hL}^{-1}$. In the study, the juice ratio was between $30.42 \%$ and $50.37 \%$ and the syrup yield was between 409.0 and $931.7 \mathrm{~L} \mathrm{da}^{-1}$. The sugar yield ranged from 347.7 to $792.0 \mathrm{~kg} \mathrm{da}^{-1}$ and the bioethanol yield from 185.1 to $421.6 \mathrm{~L} \mathrm{da}^{-1}$. It was determined that Theis, M81-E, Dale, Smith, Tracy and UNL-Hybrid3 sweet sorghum genotypes gave higher values than other ones in terms of biofuel characteristics such as stalk yield, plant juice yield, water-soluble dry matter ratio, sugar yield and ethanol yield values.

\section{Giriş}

Dünya'da ve ülkemizde artan enerji ihtiyacı ve hıla tükenen fosil enerji kaynakları, yenilenebilir enerji kaynaklarının önemini arttırmıştır. Tatlı sorgum, yenilenebilir enerji elde etmek için kullanılabilecek önemli bir bitkidir (Öktem ve ark., 2018). İnsan beslenmesinde ve hayvan yemi olarak da kullanılabilmektedir (Buxton ve ark., 1999; Koppen ve ark., 2009). Tatlı sorgumun saplarından elde edilen şırasından (etanol üretimi için), sapından (enerji üretimi, plastik üretimi), tanesinden (hayvan yemi ve etanol üretimi için) yararlanılmaktadır. Tatlı sorgum küspesi ve yeşil yaprakları mükemmel bir yem, organik gübre, sanayide selülozik hammadde ve kağıt hamuru kaynağı olarak geniş kullanım alanlarına sahiptir (Almoderes ve Goli, 2013). Tatlı sorgumun kullanım alanları Dünyada her geçen gün artmaktadır. Tatlı sorgum bitkisi Poaceae familyasına ait $\mathrm{C} 4$ fotosentez grubunda bulunan tek yıllık bir enerji bitkisidir. Orijini Doğu ve Kuzey Afrika'dır. Güçlü ve hızlı büyüme potansiyeli olup, oldukça etkili kök yapısına sahiptir. Etkili kök yapısı bitkinin kuraklığa dayanaklığını ve su ihtiyacının düşük olmasını sağlar (Koppen ve ark., 2009). Diğer bitkilere göre hastalık ve zararlılara karşı daha dirençlidir (Guiying ve ark., 2003).

Tatlı sorgum bitkisinin toplam ağırlı̆̆ının \% 70-75'i sap, \% 10-15'i yaprak, \% 10'u kök ve \% 7'si tane kısmından oluşmaktadır (Grassi, 2001). Bu oranlar çeşide, kültürel yöntemlere ve özellikle bitki sıklığına bağlı olarak değişmektedir. Tatlı sorgum bitkisinin şeker içeriği yüksektir. En fazla şeker sapta (\% 78.7) bulunmakta olup, fruktoz, glikoz ve sakkaroz gibi 14 'ten fazla şeker türünü içermektedir. Saptaki özsuyunun brix değeri (suda eriyebilir toplam kuru madde miktarı) bitkinin ekildiği alana, çeşide ve hasat dönemine bağlı olarak değişmektedir.

Enerji bitkisi olmasının yanı sıra, iyi bir şeker kaynağıdır. Tatlı sorgum bitkisi, şeker üretiminin yapıldığı diğer bitkilerin yetişemediği yerlerde de üretilebildiğinden bu yerler açısından önemli bir avantaj oluşturabilir. Ayrıca şeker pancarı ekilen bölgelerde artan hastalıklar ve zararları azaltmak ve bitki öz suyundan etanol üretmek için şeker pancarı ile münavebe yapılabileceği bildirilmektedir (Frese, 1994). Özsuyundan fermantasyon yoluyla elde edilen etanol enerji kaynağı olarak kullanılabilir. Gomez ve ark. (2011) tatlı sorgum bitkisinden 924 ile $1051 \mathrm{~L} \mathrm{ha}^{-1}$ arasında etil alkol elde etiklerini bildirmişlerdir.

Tatlı sorgum bitkisinden elde edilen yakıtların uygun koşullarda yakılması ile havaya karışan duman içinde düşük oranda kükürt içermektedir (Dalianis ve ark., 1992). Çevre kirliliğinin artması ve enerji ihtiyacının fazla olması göz önüne alındığında, tatlı sorgum bitkisinin ciddi oranda faydalı olabileceği görülebilmektedir.

Günümüzde enerji alanında dışa bağımlı olmamak için birçok ülke enerji ihtiyaçlarını karşılamak için alternatif enerji kaynaklarına yönelmeye ve bu yönde yatırım yapmaya başlamışlardır. Fosil kaynaklarının yakın zamanda tükeneceği de göz önüne alındığında enerji ihtiyacının karşılanması için sürdürülebilir ve alternatif çözümler üretmek vazgeçilmez bir ihtiyaçtır. Hem temiz hem de sürdürülebilir enerji özelliği olan bitkilerden etanol elde edilmesi üzerinde durulması gereken bir konudur. Özellikle tatlı sorgum bitkisinin enerji bitkisi olarak kullanılarak etanol üretilmesi ve etanolün alternatif enerji kaynağı olarak kullanılması yönüyle tatlı sorgum önemli bir konuma yükselmiştir (Öktem ve Öktem, 2018). Dünya da tatlı sorgum'un enerji bitkisi olarak kullanılmasına karşın, Türkiye'de yeni tanınmaya başlamıştır. Tatlı sorgum bitkisinin ülkemizde ve GAP bölgesinde yaygınlaşması ile bioetanol üretimi artarak ülkemizin ekonomisine katkı sağlanabilecektir.

Sorgum bitkisinde olgunluk sınıfları erken/orta, geç ve çok geç olarak tanımlanmış olup, genel olarak erkenci/orta genotipler 85-105 gün, geçci genotipler 120-150 gün, çok geçci genotipler ise 130-160 gün arasında olgunlaşırlar (Burks, 2012). Araştırmada geç olgunlaşma süresine sahip bazı tatlı sorgum genotiplerinin Harran Ovası koşullarına adaptasyon kabiliyetlerinin belirlenmesi, verim potansiyellerinin ortaya çıkarılması, biyoyakıt kaynağı olarak kullanılabilme imkânlarının araştııılması ve kullanılan çeşitlerin verim ve biyoyakıt ögelerinin belirlenmesi amaçlanmıştır.

\section{Materyal ve Yöntem}

Çalışma Harran Üniversitesi Ziraat Fakültesi Eyyübiye Araştırma ve Uygulama alanında 2019 yılında ana ürün yetiştirme koşullarında yürütülmüştür. Denemede bitki materyali olarak geç olgunlaşma süresine sahip Brandes, Corina, Dale, Grassi, M81-E, P1579753, Ramada, Rio, Roma, Smith, Theis, Topper 76-I, Topper 76-II, Tracy, UNL-Hybrid-3 ve Gülşeker gibi 16 adet tatlı sorgum genotipi kullanılmıştır. Gülşeker yerli ve standart çeşit olup, diğerleri Amerika Birleşik Devletlerinden temin edilmiştir. 
Çizelge 1. Deneme alanına ait bazı toprak özellikleri

Table 1. Some soil characteristics of the research area

\begin{tabular}{cccccccccc}
\hline $\begin{array}{c}\text { Derinlik } \\
(\mathrm{cm})\end{array}$ & $\begin{array}{c}\text { Hacim } \\
\text { Ağıllığ } \\
\left(\mathrm{g} / \mathrm{cm}^{3}\right)\end{array}$ & $\begin{array}{c}\text { Organik } \\
\text { Madde } \\
(\%)\end{array}$ & $\begin{array}{c}\text { Kum } \\
(\%)\end{array}$ & $\begin{array}{c}\text { Silt } \\
(\%)\end{array}$ & $\begin{array}{c}\text { Kireç } \\
(\%)\end{array}$ & $\mathrm{pH}$ & $\begin{array}{c}\mathrm{N} \\
\left(\mathrm{kg} \mathrm{ha}^{-1}\right)\end{array}$ & $\begin{array}{c}\mathrm{P}_{2} \mathrm{O}_{5} \\
\left(\mathrm{~kg} \mathrm{ha}^{-1}\right)\end{array}$ & $\begin{array}{c}\mathrm{K}_{2} \mathrm{O} \\
\left(\mathrm{kg} \mathrm{ha}^{-1}\right)\end{array}$ \\
\hline $0-30$ & 1.37 & 1.2 & 7 & 34 & 59 & 7.3 & 25 & 27 & 1280 \\
$30-60$ & 1.40 & 0.8 & 17 & 25 & 58 & 7.2 & 12 & 20 & 900 \\
$60-90$ & 0.6 & 0.6 & 20 & 21 & 59 & 7.2 & 6 & 17 & 810 \\
\hline
\end{tabular}

Çizelge 2. Şanlıurfa'da 2019 yılın tatlı sorgum büyüme dönemindeki aylık bazı iklim verileri Table 2. Monthly some climatic datas during 2019 sweet sorghum growth period in Sanliurfa

\begin{tabular}{lllllll}
\hline Aylar & $\begin{array}{l}\text { Ortalama } \\
\text { sicaklık } \\
\left({ }^{\circ} \mathrm{C}\right)\end{array}$ & $\begin{array}{l}\text { En yüksek } \\
\text { S1caklık } \\
\left({ }^{\circ} \mathrm{C}\right)\end{array}$ & $\begin{array}{l}\text { En düşük } \\
\text { sicaklık } \\
\left({ }^{\circ} \mathrm{C}\right)\end{array}$ & $\begin{array}{l}\text { Ortalama } \\
\text { Nisbi Nem } \\
(\%)\end{array}$ & $\begin{array}{l}\text { Ortalama } \\
\text { güneşlenme } \\
\text { süresi (saat) }\end{array}$ & $\begin{array}{c}\text { Yağış } \\
\text { miktarı } \\
(\mathrm{mm})\end{array}$ \\
\hline Nisan & 14.4 & 26.8 & 5.9 & 67.0 & 7.6 & 97.4 \\
Mayıs & 25.2 & 40.3 & 10.1 & 35.8 & 11.1 & 7.3 \\
Haziran & 30.7 & 44.1 & 18.5 & 30.6 & 11.8 & 8.9 \\
Temmuz & 31.7 & 42.3 & 19.7 & 29.6 & 12.4 & 0.0 \\
Ağustos & 32.8 & 45.8 & 20.7 & 29.3 & 11.3 & 0.0 \\
Eylül & 27.9 & 39.5 & 15.9 & 30.3 & 10.4 & 0.2 \\
Ekim & 22.9 & 36.2 & 11.3 & 44.9 & 7.4 & 45.1 \\
Kasim & 12.8 & 18.7 & 8.4 & 72.5 & 5.9 & 44.9 \\
\hline
\end{tabular}

*Şanlıurfa Meteoroloji Müdürlüğü 2019 Yılı Bülteni (Anonim, 2019)

Deneme alanı toprağı bölgede geniş yayılım gösteren Harran toprak serisinde bulunmaktadır. Bu çeşit toprakların ana materyali alüvyon olup killi ve derin profilli düz ve düze yakın topraklardır. Tipik kırmızı profilleri kil tekstürlü ve bütün profil oldukça kireçlidir (Dinç ve ark., 1988). Deneme alanından alınan toprak örneklerinde yapılan bazı fiziksel ve kimyasal analiz değerleri Çizelge 1'de verilmiştir. Çizelge 1'den deneme alanına ait toprak özellikleri incelendiğinde; organik madde ve azot bakımından fakir, potasyum miktarı yüksek, alkali yapıda, tuzluluk düzeyinin düşük ancak kireç oranının yüksek olduğu görülmektedir.

Şanlıurfa ili Güneydoğu Anadolu iklim bölgesinde bulunmaktadır. Kısmen Akdeniz ikliminin de etkisi görülebilir. Yazları sıcak ve kurak kışları 1lık bir iklime sahiptir. Yaz aylarında yağış miktarı yok denecek kadar az olup hava nispi nemi \% 50'nin altındadır. Denemenin yürütüldüğü aylara ait bazı iklim değerlerinin yer aldığ 1 Çizelge 2'de görüldüğü gibi haziran ve temmuz aylarında sıcaklık $40{ }^{\circ} \mathrm{C}$ 'nin üzerine, ağustos ayında ise $45^{0} \mathrm{C}$ 'nin üzerine çıkmıştır. Bu aylarda hava nisbi nemi ise \% 30 civarında gerçekleşmiştir. Haziran ayında $8.9 \mathrm{~mm}$ yağış görülürken, temmuz ve ağustos aylarında ise hiç yağış kaydedilmemiş̧ir.

Deneme tesadüf blokları deneme deseninde 3 tekerrürlü olarak yürütülmüştür. Deneme alanı, nisan ayı içerisinde pullukla $20-25 \mathrm{~cm}$ derinlikte sürülmüş, goble disk ile kesekler parçalandıktan sonra tapan çekilerek toprak düzleştirilip ekime uygun tohum yatağı hazırlanmıştır. Denemede her parsel $5 \mathrm{~m}$ uzunluğunda ve 4 sıradan oluşmuş olup, sıra aras1 $70 \mathrm{~cm}$ sıra üzeri ise $15 \mathrm{~cm}$ olacak biçimde daha önce hazırlanan sırtlara her ocağa 2'şer tohum bırakılarak 2-4 cm derinliğe 24 Nisan 2019'da elle ekim yapılmıştır.

Ekimden sonra yağmurlama ile sulama yapılarak çıkış sağlanmıştır. Ekimden önce taban gübresi olarak $5 \mathrm{~kg} \mathrm{da}^{-1}$ saf fosfor ve $5 \mathrm{~kg} \mathrm{da}^{-1}$ saf azot uygulanmıştır. Bitkiler 40-50 cm'ye ulaştığında ise $15 \mathrm{~kg} \mathrm{da}^{-1}$ saf azot üst gübre olarak verilmiştir (Girgin, 2012). Çimlenme gerçekleştikten sonra bitkiler 15-20 cm iken tekleme ardından el çapası ve daha sonra da traktör çapası yapılmıştır. İlk traktör çapası bitkiler $15-25 \mathrm{~cm}$ arasında iken, 2. traktör çapası ise bitkiler $40 \mathrm{~cm}$ iken yapılmıştır. Yabancı ot yoğunluğuna göre yabancı otlarla mekanik mücadele yapılmıştır. Çıkıştan sonra bitkilerin su ihtiyacına göre 10-12 gün arayla karık sulama yapılmıştır.

Bitkilerin hasadı, her bir genotipin olgunlaşma süresi dikkate alınarak bitkilerde tanenin süt olum-sarı döneminde yapılmıştır (Naoyuki and Yusuke, 2004). Hasatta, parsel başından $0.5 \mathrm{~m}$ ve kenardaki birer sıra kenar 
tesiri olarak bırakıldıktan sonra ortadaki 2 sıra hasat edilmiştir $\left(2 \times 0.7 \times 4=5.6 \mathrm{~m}^{2}\right)$.Üç silindirli ezici bir makine kullanılarak tatlı sorgum bitkisinin sapları ezilerek bitki özsuyu çıkartılmıştır. Bitki özsuyu sıkıldıktan sonra dereceli plastik tüp ile $\mathrm{mL}$ cinsinden ölçülmüştür. Bitki özsuyu saplardan sıkıldıktan hemen sonra özsuyunun toplam çözünür kuru madde (Brix) içeriği bir refraktometre (Atago, 2021) kullanılarak ölçülmüştür. Şurup verimi, özsu verimi ile brix değerinin çarpılmasıyla hesaplanmıştır. Şeker verimi ise şurup verimi ile fermantasyon etkinliği olan 0.85 ile çarpılmasıyla bulunmuştur (Jia ve ark., 2013). Etanol verimi aşağıda verilen denklem kullanılarak hesaplanmıştır. $\mathrm{EtOH}=$ [(toplam şeker / 5.68) x 3.78] x 0.8 (Bunphan ve ark., 2015; Öktem ve ark., 2018). Denemede elde edilen veriler varyans analizine tabi tutulmuş, ortalamalar arasındaki farklılıklar ise \% 5 seviyesinde DUNCAN testine göre belirlenmiştir (Yurtsever, 1984).

\section{Bulgular ve Tartışma}

Tatlı sorgum çeşitlerinin Harran Ovası ana ürün koşullarında salkım çıkarma süresi, fizyolojik olgunlaşma süresi, sap ağırlığı ve özsu verimine ait varyans analiz sonuçları Çizelge 3 'te verilmiştir. Çizelge 3 'te görüldüğg̈ gibi genotipler arasında salkım çıkarma süresi, fizyolojik olgunlaşma süresi, sap verimi ve özsu verimi bakımından istatiksel açıdan 0.01 önem düzeyinde farkl1lık olduğu tespit edilmiştir $(\mathrm{P} \leq 0.01)$.

\subsection{Salkım çıkarma süresi (gün)}

Çizelge 4' de salkım çıkarma süreleri incelendiğinde ortalama salkım çıkarma süresinin 91.06 gün olduğu görülmektedir. Salkım çıkarma süresinin en kısa olduğu değer 72.3 gün ile Gülşeker genotipinde bulunmuştur. En uzun salkım çıkarma süresi ise 102.3 gün ile Topper 76-I genotipinde saptanmıştır. Salkım çıkarma süresi bakımından genotipler arasında 30 günlük geniş bir varyasyon olduğu görülmüştür. Salkım çıkarma süresi uzun olan genotiplerin vejetasyon süresi daha uzun olduğundan daha uzun süre fotosentez yaparak daha fazla asimilant ürettikleri için verim değerleri de yüksek olmaktadır. Mülayim ve ark. (2009), Konya'da yürüttükleri bir araştırmada bulgularımıza benzer olarak en kısa salkım çıkarma süresini 74 gün olarak gözlediklerini belirtmişlerdir. Reddy ve ark. (2005) Patancheru-Hindistan iklim şartlarında farklı tatlı sorgum çeşitleriyle yürüttükleri bir araştırmada çeşitlerin 64 ile 84 gün arasında salkım çıkardıklarını belirtmişlerdir.

\subsection{Fizyolojik olgunlaşma süresi (gün)}

Çizelge 4' den fizyolojik olgunlaşma süresi değerleri incelendiğinde ortalama fizyolojik olgunlaşma süresi değerinin 151.56 gün olduğu, en kısa fizyolojik olgunlaşma süresi değeri 128 gün ile Gülşeker, en uzun fizyolojik olgunlaşma süresinin ise 168 gün ile Topper 76-I genotipinde bulunmuştur. Bulgularımıza benzer olarak Dogget (1988) fizyolojik olgunlaşma süresinin 90-140 gün arasında olduğunu bildirmişlerdir. Fizyolojik olgunlaşma süresinin uzun olması, bitkinin daha uzun süre fotosentez yaparak kuru madde üretmesine imkân tanıdığından verim ve ögelerini artırıcı yönde etki yapmaktadır.

\subsection{Sap verimi $\left(\mathrm{kg} d a^{-1}\right)$}

Çizelge 4 'den sap verimlerini incelediğimizde sap veriminin 5763.3 ile $14433.2 \mathrm{~kg} \mathrm{da}^{-1}$ arasında değiştiği görülmektedir. Ortalama sap verimi ise $10058.2 \mathrm{~kg} \mathrm{da}^{-1}$ olarak hesaplanmıştır. Çeşitler arasında en düşük sap verimi $5763.3 \mathrm{~kg} \mathrm{da}^{-1}$ ile Ramada çeşidinde, en yüksek sap verim ise $14433.2 \mathrm{~kg} \mathrm{da}^{-1}$ ile Theis çeşidinden elde edilmiştir (Şekil 1). Bulgularımızdan daha düşük olarak Chavan ve ark. (2009) yaptıkları bir araştırmada sap verimini 2276 ile $4485 \mathrm{~kg} \mathrm{da}^{-1}$ arasında değiştiğini belirtmişlerdir. Almoderes ve ark. (2007) İran ekolojik şartlarında üç faklı tatlı sorgum varyetesi (Rio, Vespa, IS2325) ile yürüttükleri bir araştırmada sap verimlerinin çeşitler arasında 3235 ile $6285 \mathrm{~kg} \mathrm{da}^{-1}$ arasında değiştiğini bildirmişlerdir.

Almoderes ve ark. (2008) tarafından İsfahan-İran koşullarında yürütülen bir başka araştırmada ise en yüksek sap veriminin $6743 \mathrm{~kg} \mathrm{da}^{-1}$ olarak Keller çeşidinden elde edildiği belirtilmiştir. Tsuchihashi ve Goto (2004) JavaEndonezya şartlarında üç tatlı sorgum varyetesinde (Keller, Rio, Wray) yürüttükleri bir araştırmada sap veriminin 4790 ile $6593 \mathrm{~kg} \mathrm{da}^{-1}$ arasında değiştiğini bildirmişlerdir. 
Çizelge 3. Salkım çıkarma süresi, fizyolojik olgunlaşma süresi, sap verimi ve özsu verimi özelliklerine ait varyans analiz değerleri

Table 3. Variance analysis values for duration of panicle formation, duration of physiological maturation, stalk yield, grain yield, plant juice yield characteristics

\begin{tabular}{|c|c|c|c|c|c|}
\hline \multirow[b]{2}{*}{$\begin{array}{l}\text { Varyasyon } \\
\text { kaynağ } 1\end{array}$} & \multirow[b]{2}{*}{$\begin{array}{c}\text { Serbestlik } \\
\text { derecesi }\end{array}$} & \multicolumn{4}{|c|}{ Kareler Ortalaması } \\
\hline & & $\begin{array}{l}\text { Salkım çıkarma } \\
\text { süresi (gün) }\end{array}$ & $\begin{array}{c}\text { Fizyolojik } \\
\text { olgunlaşma } \\
\text { süresi (gün) }\end{array}$ & $\begin{array}{c}\text { Sap verimi } \\
\left(\mathrm{kg} \mathrm{da}^{-1}\right)\end{array}$ & $\begin{array}{c}\text { Özsu verimi } \\
\left(\mathrm{L} \mathrm{da}^{-1}\right)\end{array}$ \\
\hline Tekerrür & 3 & 11.4375 & 0.0625 & 338534.5 & 74555.5 \\
\hline Çeşit & 15 & $266.76528^{* *}$ & $286.2986^{* *}$ & $17099689.2 * *$ & $3757625.6^{* *}$ \\
\hline Hata & 30 & 4.015276 & 0.04027 & 218874.16 & 52221.93 \\
\hline Genel & 47 & & & & \\
\hline Varyasyon & (\%) & 2.200 & 0.1324 & 4.651 & 5.414 \\
\hline
\end{tabular}

**; $\mathrm{P} \leq 0.01$ düzeyinde önemli

Çizelge 4. Salkım çıkarma süresi, fizyolojik olgunlaşma süresi, sap verimi ve özsu verimine özelliklerine ait değerler ve oluşan istatistiksel gruplar

Table 4. Values and statistical groups for duration of panicle formation (day), duration of physiological maturation, stalk yield and plant juice yield characteristics

\begin{tabular}{lllll}
\hline Çeşitler & $\begin{array}{l}\text { Salkı̈m çikarma } \\
\text { süresi (gün) }\end{array}$ & $\begin{array}{l}\text { Fizyolojik } \\
\text { olgunlaşma } \\
\text { süresi (gün) }\end{array}$ & $\begin{array}{l}\text { Sap verimi } \\
\left(\mathrm{kg} \mathrm{da}^{-1}\right)\end{array}$ & $\begin{array}{l}\text { Özsu verimi } \\
\left(\mathrm{L} \mathrm{da}^{-1}\right)\end{array}$ \\
\hline 1. Brandes & $101.0 \mathrm{ab}$ & $160 \mathrm{c}^{\dagger}$ & $7444.5 \mathrm{l}$ & $3291.22 \mathrm{fg}$ \\
2. Corina & $94.0 \mathrm{~cd}$ & $144 \mathrm{j}$ & $9931.3 \mathrm{def}$ & $4066.61 \mathrm{e}$ \\
3. Dale & $74.0 \mathrm{f}$ & $146 \mathrm{1}$ & $12202.1 \mathrm{bc}$ & $6149.14 \mathrm{a}$ \\
4. Grassi & $94.0 \mathrm{~cd}$ & $158 \mathrm{~d}$ & $11313.9 \mathrm{~cd}$ & $4768.23 \mathrm{~cd}$ \\
5. M81-E & $97.0 \mathrm{abc}$ & $151 \mathrm{~g}$ & $12990.1 \mathrm{~b}$ & $5685.72 \mathrm{ab}$ \\
6. P1579753 & $95.0 \mathrm{bcd}$ & $156 \mathrm{e}$ & 7555.41 & $3117.26 \mathrm{~g}$ \\
7. Ramada & $94.3 \mathrm{~cd}$ & $162 \mathrm{~b}$ & $5763.3 \mathrm{j}$ & $2341.07 \mathrm{~h}$ \\
8. Rio & $83.3 \mathrm{e}$ & $147 \mathrm{~h}$ & $10332.6 \mathrm{def}$ & $3142.09 \mathrm{~g}$ \\
9. Roma & $95.6 \mathrm{bc}$ & $154 \mathrm{f}$ & $7784.9 \mathrm{hl}$ & $3237.83 \mathrm{fg}$ \\
10. Smith & $94.3 \mathrm{~cd}$ & $146 \mathrm{1}$ & $9674.9 \mathrm{efg}$ & $4134.09 \mathrm{de}$ \\
11. Theis & $76.3 \mathrm{f}$ & $142 \mathrm{k}$ & $14433.2 \mathrm{a}$ & $6020.27 \mathrm{ab}$ \\
12. Topper 76-I & $102.3 \mathrm{a}$ & $168 \mathrm{a}$ & $9602 \mathrm{fg}$ & $4389.27 \mathrm{de}$ \\
13. Topper 76-II & $89.0 \mathrm{de}$ & $160 \mathrm{c}$ & $8477.1 \mathrm{ghl}$ & $3733.91 \mathrm{efg}$ \\
14. Tracy & $97.0 \mathrm{abc}$ & $146 \mathrm{1}$ & $13245.8 \mathrm{ab}$ & $5337.05 \mathrm{bc}$ \\
15. UNL-Hybrid-3 & $97.3 \mathrm{abc}$ & $156 \mathrm{e}$ & $9149.1 \mathrm{fgh}$ & $4208.54 \mathrm{de}$ \\
16. Gülşeker & $72.3 \mathrm{f}$ & $128 \mathrm{l}$ & $11030.8 \mathrm{cde}$ & $3907.97 \mathrm{ef}$ \\
Ortalama & 91.06 & 151.56 & 10058.2 & 4220.65 \\
LSD & 6.098 & 0.6108 & 1423.81 & 695.475 \\
\hline
\end{tabular}

†; Aynı harf ile gösterilen değerler arasında Duncan testine göre $P \leq 0.05$ seviyesinde istatistiksel olarak önemli fark yoktur

\section{4. Özsu verimi $\left(L d a^{-1}\right)$}

Çizelge 4 'de özsu verimi incelendiğinde, özsu veriminin 2341.07 ile $6149.14 \mathrm{~L} \mathrm{da}^{-1}$ arasında değiştiği görülmektedir. Ortalama özsu verimi değeri $4220.646 \mathrm{~L} \mathrm{da}^{-1}$ olarak tespit edilmiştir. Özsu veriminin en düşük olduğu değer $2341.07 \mathrm{~L} \mathrm{da}^{-1}$ ile Ramada genotipinde bulunmuştur. 


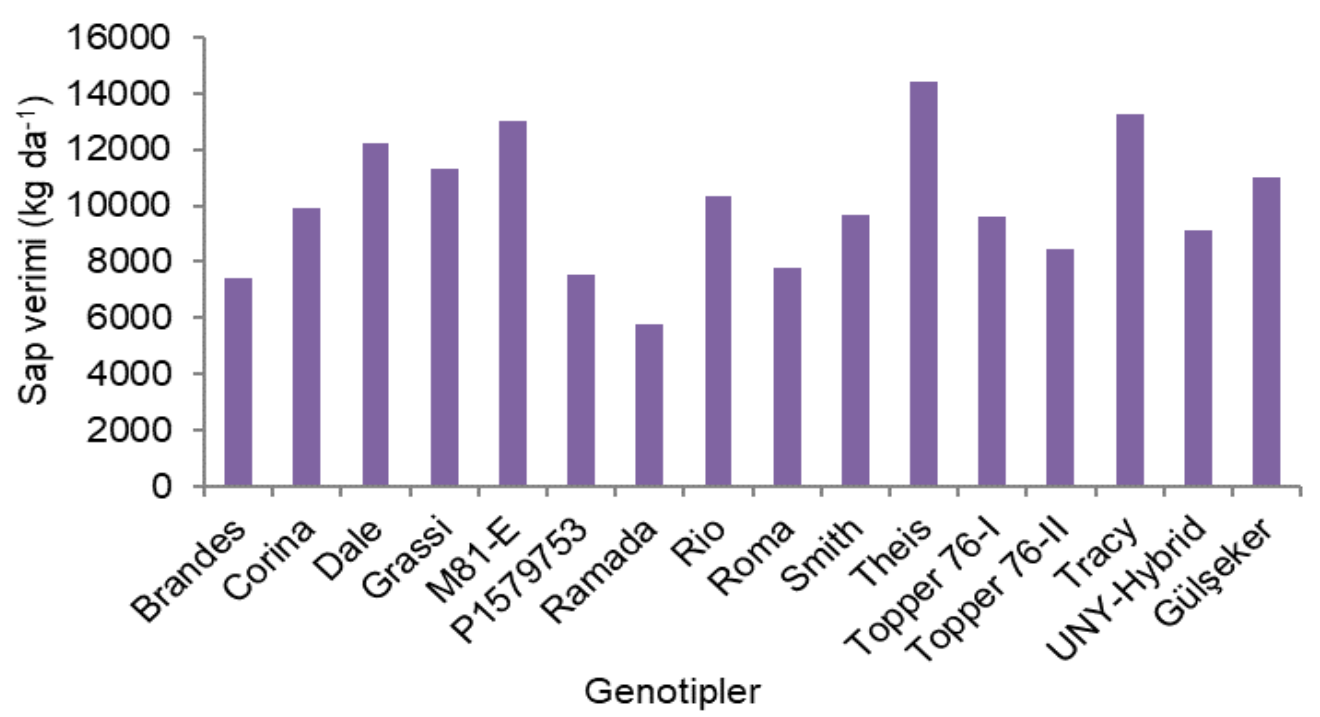

Şekil 1. Tatlı sorgum genotiplerinin sap verimi değerleri.

Figure 1. Stalk yield values of sweet sorghum genotypes.

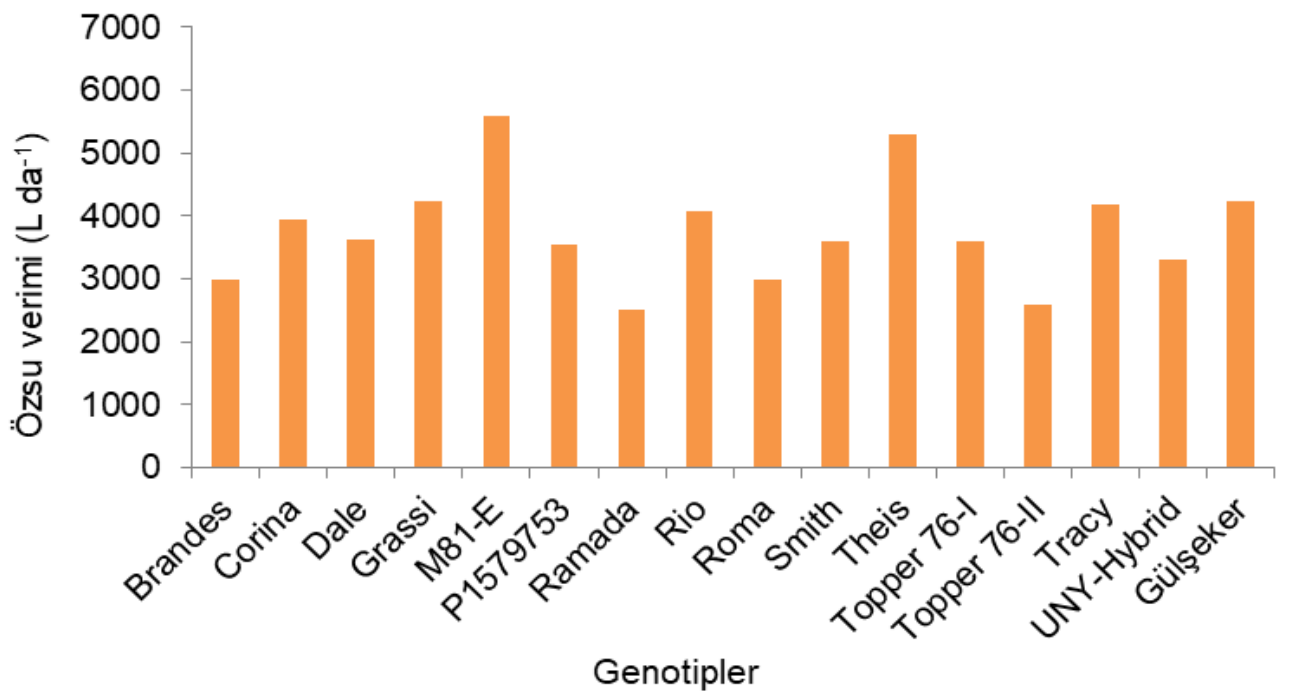

Şekil 2. Tatlı sorgum genotiplerinin özsu verimi değerleri.

Figure 2. Juice yield values of sweet sorghum genotypes.

Özsu veriminin en fazla olduğu değer ise $6149.14 \mathrm{~L} \mathrm{da}^{-1}$ ile Dale genotipinde tespit edilmiştir (Şekil 2). Dale genotipine en yakın özsu değerleri ise sırasıyla 5685.72 ve $6020.27 \mathrm{~L} \mathrm{da}^{-1}$ ile M81-E ve Theis genotiplerinde gözlenmiştir. Özsu verimi ve brix değeri yüksek genotiplerin şeker ve biyoetanol verimleri de yüksek olmaktadır. $\mathrm{Bu}$ açıdan değerlendirildiğinde özsu verimi önemli bir biyoyakıt unsurudur. Sap verimi yüksek olan genotiplerin özsu verimleri de yüksek bulunmuştur.

Bazı araştırmacılar yaptıkları çalışmalarda bulgularımıza benzer sonuçlar tespit etmişlerdir. Rutto ve ark. (2013) Dale çeşidinde özsu veriminin 1200 ile $2110 \mathrm{~L} \mathrm{da}^{-1}$ arasında ve M81-E çeşidinde 1290 ile $2340 \mathrm{~L} \mathrm{da}^{-1}$ arasında değiştiğini saptamışlardır. Cole ve ark. (2017) ortalama özsu verimini Dale için $1835.9 \mathrm{~L} \mathrm{da}^{-1}$, M81-E için 2564.6 L $\mathrm{da}^{-1}$ ve Theis için $2000.7 \mathrm{~L} \mathrm{da}^{-1}$ olarak bulmuşlardır. Horton (2011), Dale, M81-E ve Theis için sırasıyla 3817.4 L $\mathrm{da}^{-1}, 1517.49 \mathrm{~L} \mathrm{da}^{-1}, 402.48 \mathrm{~L} \mathrm{da}^{-1}$ özsu değerleri elde etmişlerdir. Reddy ve ark. (2005) Patancheru-Hindistan iklim şartlarında, farklı tatlı sorgum çeşitleriyle yürüttükleri bir araştırmada özsu verimlerinin 1210 ile $1850 \mathrm{~L} \mathrm{da}^{-1}$ 
arasında değiştiğini belirtmişlerdir. Genotiplerin farklı çevrelerde değişik değerlere ulaşması, farklı iklim, toprak ve yetiştirme koşullarından kaynaklanmaktadır.

Tatlı sorgum çeşitlerinin Harran Ovası ana ürün koşullarında suda çözünür kuru madde (brix), tane verimi, bin tane ağırlı̆̆ı ve hektolitre ağırlığına ait varyans analiz sonuçları Çizelge 5'te verilmiştir. Çizelgede 5'te görüldüğg̈ gibi genotipler arasında suda çözünür kuru madde, tane verimi, bin tane ağırlığı ve hektolitre ağırlığı bakımından istatiksel açıdan 0.01 önem düzeyinde farklılık olduğu tespit edilmiştir $(\mathrm{P} \leq 0.01)$.

\subsection{Suda çözünür kuru madde oranı - Brix (\%)}

Çizelge 6'da görüldüğü gibi suda çözünür kuru madde oranları (Brix) \% 13.36 ile \% 20.40 arasında değişmiştir. Genotiplerin ortalama suda çözünür kuru madde oranı \% 15.88 olarak belirlenmiştir. Genotipler arasında en düşük brix oranı \% 13.36 ile Dale çeşidinde saptanmıştır. En yüksek brix oranı ise \% 20.40 ile Smith çeşidinde gözlenmiş olup, onu \% 18.43 ile Rio çeşidi izlemiştir (Şekil 3). Brix değerinin yüksek olması bitki özsuyunda şeker oranının yüksek olduğunun göstergesidir. Yüksek brix değeri ve yüksek özsuyu miktarının bir araya geldiği genotiplerin biyoetanol verimleri de yüksek olmaktadır. Bulgularımıza benzer olarak Subramanian (2013) yaptığı bir çalışmada brix değerlerinin \% 6.2 ile 20.7 arasında farklılık gösterdiğini saptamıştır. Almoderes ve ark. (2007) İran ekolojik şartlarında üç faklı tatlı sorgum varyetesi (Rio, Vespa, IS2325) ile yürüttükleri bir araştırmada brix değerlerinin \% 14.2 ile 17.1 arasında değiştiğini bildirmişlerdir. Tsuchihashi ve Goto (2004) tatlı sorgum bitkisinde brix değerini \% 11.4 ile 15.6 arasında bildirmişlerdir.

\subsection{Tane verimi $\left(\mathrm{kg} \mathrm{da}^{-1}\right)$}

Çizelge 6'da tane verimi değerlerini incelediğimizde, genotipler arasında tane veriminin 82.97 ile $328.18 \mathrm{~kg} \mathrm{da}^{-1}$ arasında değişstiği görülmektedir. Ortalama tane verimi $158.12 \mathrm{~kg} \mathrm{da}^{-1}$ olarak belirlenmiştir. En düşük tane verimi $82.97 \mathrm{~kg} \mathrm{da}^{-1}$ ile Ramada çeşidinde, en yüksek değer ise $328.18 \mathrm{~kg} \mathrm{da}^{-1}$ ile M81-E çeşidinde saptanmıştır (Şekil 4). İncelenen genotipler arasında tane verimi yönünden büyük varyasyon olduğu görülmektedir. Bazı genotiplerin küçük salkımlı ve küçük taneli olmasından kaynaklanan düşük tane verimi değerleri gözlenmiştir. Tane verimi genotipik faktörler yanında iklim, toprak ve tarımsal uygulamalardan etkilenmektedir.

Bulgularımıza benzer olarak Avcı ve ark. (2018) yaptıkları çalışmada tane verimini 223 ile $480 \mathrm{~kg} \mathrm{da}^{-1} \mathrm{arasında}$ elde etmişlerdir. Zhao ve ark. (2009) beş farklı tatlı sorgum çeşidinde tane veriminin 220 ile $570 \mathrm{~kg} \mathrm{da}^{-1}$ arasında değiştiğini belirtmişlerdir. Reddy ve ark. (2005) Patancheru-Hindistan iklim şartlarında, farklı tatlı sorgum çeşitleriyle yürüttükleri bir araştırmada tane verimlerinin 20 ile $650 \mathrm{~kg} \mathrm{da}^{-1}$ arasında değişim gösterdiğini açıklamışlardır. Tsuchihashi ve Goto (2004) Java-Endonezya şartlarında üç tatı sorgum varyetesinde (Keller, Rio, Wray) yürütülen bir araştırmada, çeşitlerin tane veriminin 228 ile $238 \mathrm{~kg} \mathrm{da}^{-1}$ arasında değiştiğini belirtmişlerdir.

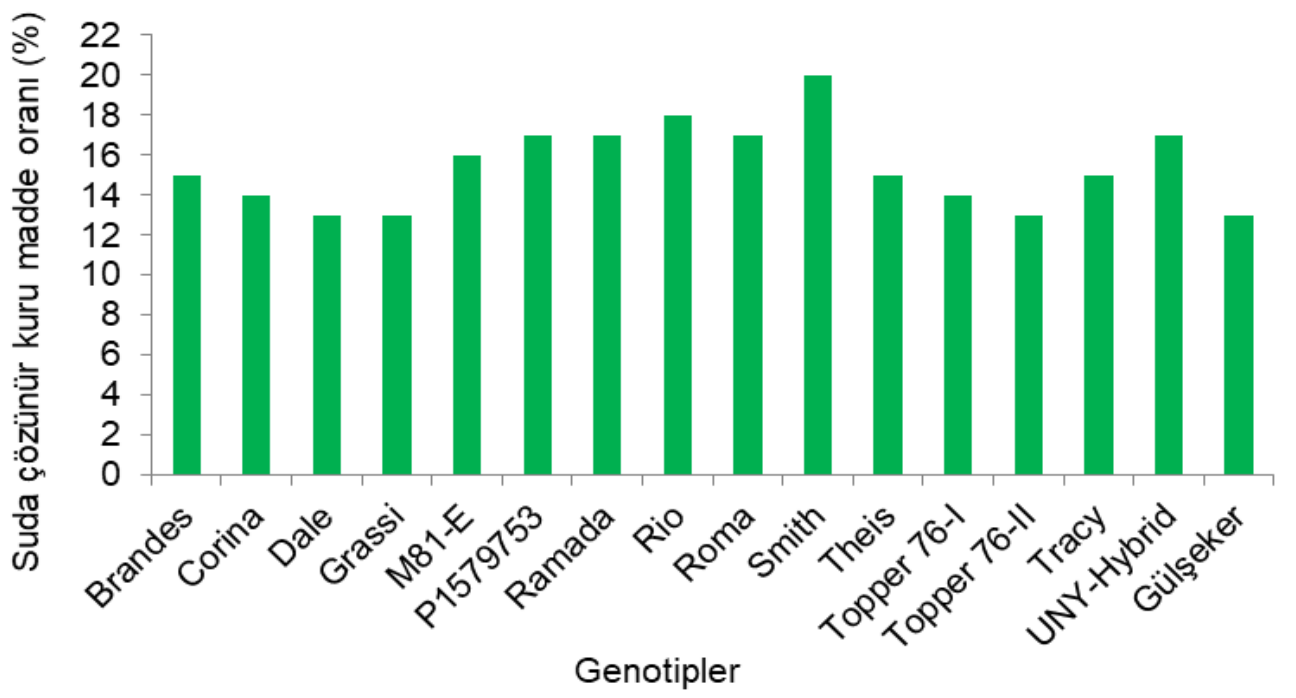

Şekil 3. Tatlı sorgum çeşitlerinin suda çözünür kuru madde oranı değerleri.

Figure 3. Water soluble dry matter ratio values of sweet sorghum varieties. 


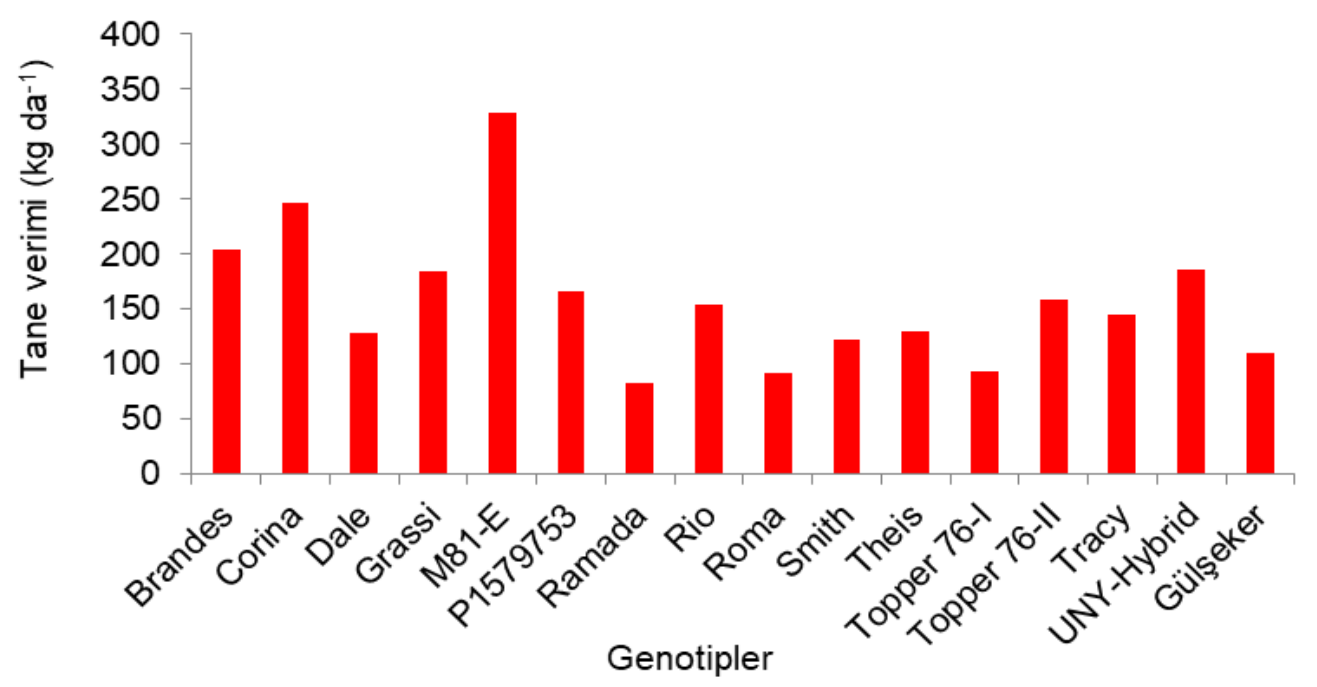

Şekil 4. Tatlı sorgum genotiplerinin tane verimi değerleri.

Figure 4. Grain yield values of sweet sorghum genotypes.

\subsection{Bin tane ağırlı̆gl $(g)$}

Çizelge 6'de bin tane ağırlığı değerleri incelendiğinde bin tane ağırlığının $15.41 \mathrm{~g}$ ile $45.13 \mathrm{~g}$ arasında değiştiği görülecektir. Genotiplerin ortalama bin tane ağırlığı değeri ise $26.65 \mathrm{~g}$ olarak hesaplanmıştır. En düşük bin tane ağılığı değeri $15.41 \mathrm{~g}$ ile Tracy genotipinde, bin tane ağırlığının en yüksek olduğu değer ise $45.13 \mathrm{~g}$ ile Corina genotipinde bulunmuştur. Tatlı sorgum bitkisinde bin tane ağırlığı genetik ve yetiştirme koşullarının etkisi altındadır. Bulgularımıza benzer sonuçlar bazı araştırıcılar tarafından bildirilmiştir. Acar ve Akgün (2009) ortalama bin tane ağırlığını $24.70 \mathrm{~g}$ olarak belirtirken, Samarth ve ark. (2018) ise yaptıkları çalışmada bin tane ağırlığının $31.5 \mathrm{~g}$ ile $32.6 \mathrm{~g}$ arasında değiştiğini belirtmişlerdir. Tsuchihashi ve Goto (2004) üç tatlı sorgum varyetesinde (Keller, Rio, Wray) yürütülen bir araştırmada bin tane ağırlığının $81.0 \mathrm{~g}$ ile $93.4 \mathrm{~g}$ arasında bulunduğu bildirilmiştir.

\subsection{Hektolitre ăgırlı̆g $\left(\mathrm{kg} \mathrm{hL}^{-1}\right)$}

Çizelge 6 'dan görüldüğü gibi hektolitre ağırlığı değerleri 51 ile $70 \mathrm{~kg} \mathrm{hL}^{-1}$ arasında değişmiştir. Genotiplerin ortalama hektolitre ağırlığı ise $61.47 \mathrm{~kg} \mathrm{hL}^{-1}$ olarak hesaplanmıştır. Genotipler arasında hektolitre ağırlığının en düşük olduğu değer $51 \mathrm{~kg} \mathrm{hL}^{-1}$ ile Gülşeker genotipinde tespit edilmiş olup, hektolitre ağırlığının en fazla olduğu değer ise $70 \mathrm{~kg} \mathrm{hL}^{-1}$ ile Dale genotipinde saptanmıştır. Tatlı sorgum bitkisinde hektolitre ağırlığı genetik ve yetiştirme koşullarından etkilenmektedir. Tatlı sorgum çeşitlerinin Harran Ovası ana ürün koşullarında özsu oranı, şurup verimi, şeker verimi ve etanol verimine ait varyans analiz değerleri Çizelge 7'de verilmiştir. Çizelgede 7'te görüldüğü gibi genotipler arasında özsu oranı, şurup verimi, şeker verimi ve etanol verimi bakımından istatiksel açıdan \%1 önem düzeyinde farklılık olduğu tespit edilmiştir $(\mathrm{P} \leq 0.01)$.

\section{9. Özsu oranı (\%)}

Çizelge 8'de özsu oranı değerlerini incelediğimizde, genotipler arasında özsu oranının \% 30.42 ile \% 50.37 arasında değiştiği görülmektedir (Çizelge 8). Ortalama özsu oranı \% 41.96 olarak belirlenmiştir. En düşük özsu oranı \% 30.42 ile Rio genotipinde, en yüksek değer ise \% 50.37 ile Dale genotipinde saptanmıştır. Özsu oranı yüksek olduğunda bitki saplarından elde edilen özsu miktarı da fazla olmaktadır. Genotiplerin özsu oranlarının yüksek olması istenen bir durumdur.

Rio ve Gülşeker genotipleri dışında bütün genotipler \% 40'1n üzerinde özsuyu değerleri vermiştir. Topper 76-I, UNL-Hybrid-3, Brandes, Dale ve Topper 76-II genotiplerinde diğerlerine göre daha yüksek özsu oranı değerleri gözlenmiştir. 
Çizelge 5. Suda çözünür kuru madde oranı-brix, tane verimi, bin tane ağırlığı ve hektolitre ağırlığına ait varyans analiz değerleri

Table 5. Variance analysis values for water soluble dry matter ratio-brix, grain yield, thousand kernel weight and hectoliter weight characteristics

\begin{tabular}{lccccc}
\hline \multirow{2}{*}{$\begin{array}{l}\text { Varyasyon } \\
\text { kaynağı }\end{array}$} & $\begin{array}{c}\text { Serbestlik } \\
\text { derecesi }\end{array}$ & $\begin{array}{c}\text { Suda çözünür } \\
\text { kuru madde } \\
\text { oranı - Brix (\%) }\end{array}$ & $\begin{array}{c}\text { Tane verimi } \\
\left(\mathrm{kg} \mathrm{da}^{-1}\right)\end{array}$ & $\begin{array}{c}\text { Bin tane ağırlığı } \\
(\mathrm{g})\end{array}$ & $\begin{array}{c}\text { Hektolitre ağırlığ1 } \\
\left(\mathrm{L} \mathrm{kg}^{-1}\right)\end{array}$ \\
\hline Tekerrür & 3 & 7.688 & 3.563 & 4.6987 & 0.02085 \\
Çeşit & 15 & $12.760022^{* *}$ & $12017.61^{* *}$ & $172.3872^{* *}$ & $92.0875^{* *}$ \\
Hata & 30 & 0.0030 & 338.5846 & 4.03780 & 0.020833 \\
Genel & 47 & & & & \\
Varyasyon katsayısı (\%) & & 0.351 & 11.6371 & 7.5394 & 0.2347 \\
\hline
\end{tabular}

**; $\mathrm{P} \leq 0.01$ düzeyinde önemli

\subsection{0. Şurup verimi (L da-1)}

Şurup verimi 409.0 L da-1 (Ramada) ile 931.7 L da-1 (M81-E) arasında değişmiştir (Çizelge 8). M81-E (931.7 L da-1) ve Theis (927.7 L da-1) genotipleri şurup verimi en yüksek genotipler olarak belirlenmiş ve aralarında istatistiki farklılık görülmemiştir. M81-E, Theis, Smith, Dale, Tracy, UNL-Hybrid-3 genotipleri diğerlerine göre daha yüksek şurup verimi vermişlerdir. Özsu verimi ve brix değeri yüksek olduğunda şurup verimi de artmaktadır. Şurup veriminin artması şeker ve biyoetanol verimlerinin de artmasına neden olmaktadır.

Çizelge 6. Suda çözünür kuru madde oranı-brix, tane verimi, bin tane ağırlı̆̆ı ve hektolitre ağırlığına ait değerler ve oluşan istatistiki gruplar

Table 6. Values and statistical groups for water soluble dry matter ratio-brix, grain yield, thousand kernel weight and hectoliter weight characteristics

\begin{tabular}{lllll}
\hline Çeşitler & $\begin{array}{l}\text { Suda çözünür kuru } \\
\text { madde oranı-Brix } \\
(\%)\end{array}$ & $\begin{array}{l}\text { Tane verimi } \\
\left(\mathrm{kg} \mathrm{da}^{-1}\right)\end{array}$ & $\begin{array}{l}\text { Bin tane ağırlığ } \\
(\mathrm{g})\end{array}$ & $\begin{array}{l}\text { Hektolitre ağırlığ } \\
\left(\mathrm{kg} \mathrm{hL}^{-1}\right)\end{array}$ \\
\hline 1. Brandes & $15.46 \mathrm{e}^{\dagger}$ & $203.71 \mathrm{bc}$ & $27.50 \mathrm{~cd}$ & $61 \mathrm{~h}$ \\
2. Corina & $14.43 \mathrm{f}$ & $246.43 \mathrm{~b}$ & $45.13 \mathrm{a}$ & $69 \mathrm{~b}$ \\
3. Dale & $13.36 \mathrm{~g}$ & $128.84 \mathrm{e}-\mathrm{h}$ & $20.70 \mathrm{efg}$ & $70 \mathrm{a}$ \\
4. Grassi & $13.43 \mathrm{~g}$ & $184.81 \mathrm{cde}$ & $16.51 \mathrm{fg}$ & $68 \mathrm{c}$ \\
5. M81-E & $16.40 \mathrm{~d}$ & $328.18 \mathrm{a}$ & $26.19 \mathrm{cde}$ & $58 \mathrm{j}$ \\
6. P1579753 & $17.36 \mathrm{c}$ & $165.82 \mathrm{c}-\mathrm{f}$ & $33.94 \mathrm{~b}$ & $60 \mathrm{1}$ \\
7. Ramada & $17.46 \mathrm{c}$ & $82.97 \mathrm{~h}$ & $34.48 \mathrm{~b}$ & $62 \mathrm{~g}$ \\
8. Rio & $18.43 \mathrm{~b}$ & $153.62 \mathrm{c}-\mathrm{f}$ & $21.86 \mathrm{def}$ & $65 \mathrm{e}$ \\
9. Roma & $17.40 \mathrm{c}$ & $91.23 \mathrm{gh}$ & $29.22 \mathrm{bc}$ & $56 \mathrm{k}$ \\
10. Smith & $20.40 \mathrm{a}$ & $122.52 \mathrm{fgh}$ & $28.40 \mathrm{bc}$ & $66 \mathrm{~d}$ \\
11. Theis & $15.43 \mathrm{e}$ & $129.27 \mathrm{e}-\mathrm{h}$ & $17.26 \mathrm{fg}$ & $60 \mathrm{1}$ \\
12. Topper 76-I & $14.43 \mathrm{f}$ & $93.52 \mathrm{gh}$ & $26.30 \mathrm{cde}$ & $60 \mathrm{1}$ \\
13. Topper 76-II & $13.40 \mathrm{~g}$ & $158.47 \mathrm{c}-\mathrm{f}$ & $25.32 \mathrm{cde}$ & $62 \mathrm{~g}$ \\
14. Tracy & $15.36 \mathrm{e}$ & $144.48 \mathrm{~d}-\mathrm{g}$ & $15.41 \mathrm{~g}$ & $64 \mathrm{f}$ \\
15. UNL-Hybrid-3 & $17.40 \mathrm{c}$ & $185.78 \mathrm{~cd}$ & $30.85 \mathrm{bc}$ & $52 \mathrm{l}$ \\
16. Gülşeker & $13.41 \mathrm{~g}$ & $110.20 \mathrm{fgh}$ & $27.30 \mathrm{~cd}$ & $51 \mathrm{~m}$ \\
Ortalama & 15.88 & 158.12 & 26.65 & 61.5 \\
LSD & 0.17 & 56.0 & 6.12 & 0.44 \\
\hline
\end{tabular}

†; Aynı harf ile gösterilen değerler arasında Duncan testine göre $P \leq 0.05$ seviyesinde istatistiksel olarak önemli fark yoktur. 


\subsection{1. Şeker verimi $\left(\mathrm{kg} \mathrm{da}^{-1}\right)$}

Şeker verimi 347.7 ile $792.0 \mathrm{~kg} \mathrm{da}^{-1}$ arasında değişmiştir. En yüksek şeker verimi M81-E ve Theis genotiplerinde, en düşük şeker verimi ise Ramada genotipinde gözlenmiştir. Theis, M81-E, Smith, UNL-Hybrid-3, Dale, Tracy genotipleri diğerlerine göre daha yüksek şeker verimi vermişlerdir (Çizelge 8).

Şeker, biyoetanol elde etmek için en önemli maddedir. Bitki suyundaki şeker fermantasyon yoluyla biyoetanole dönüşür. Şeker miktarı doğrudan biyoetanol miktarını etkiler. Bitki özsuyunda ne kadar fazla şeker varsa o kadar fazla biyoetanol elde edileceği anlamına gelmektedir. Tatlı sorgum üzerinde yapılan araştırmalar, şeker veriminin tatlı sorgum çeşitlerinde 286 ila $401 \mathrm{~kg} \mathrm{da}^{-1}$ arasında (Tsuchihashi ve Goto, 2004), 240 ila $290 \mathrm{~kg} \mathrm{da}{ }^{-1}$ (Reddy ve ark., 2005) ve $1320 \mathrm{~kg} \mathrm{da}^{-1}$ (Murray ve ark., 2009) arasında değiştiğini göstermiştir.

\subsection{Biyoetanol verimi $\left(L d a^{-1}\right)$}

Biyoetanol verimi $185.1 \mathrm{~L} \mathrm{da}^{-1}$ (Ramada) ile 421.6 (M81-E) $\mathrm{L} \mathrm{da}^{-1}$ arasında değişmiştir (Çizelge 8). M81-E (421.6 $\mathrm{L} \mathrm{da}^{-1}$ ) ve Theis genotipleri (419.8 $\mathrm{L} \mathrm{da}^{-1}$ ) yüksek biyoetanol verimi ile dikkat çekmektedir.

Diğer tatlı sorgum genotiplerine göre Smith, Dale, Tracy ve UNL-Hybrid-3 genotiplerinde daha yüksek biyoetanol verimi değerleri gözlenmiştir.

Saplardaki şeker içeriği ne kadar yüksek olursa, potansiyel biyoetanol verimi de o kadar yüksek olmaktadır (Öktem ve ark., 2018). Biyoetanol veriminde şurubun şeker içeriği önemli bir faktördür. Çünkü şekerler (toplam çözünür katılar) fermente olarak biyoetanol elde edilmektedir. Elde edilen biyoetanol ise biyoyakıt üretmek için fosil yakitla harmanlama maddesi olarak kullanılabilir.

Daha önce yapılmış bir araştırmada tatlı sorgumda biyoetanol verimi $768.2 \mathrm{~L} \mathrm{da}^{-1}$ olarak belirtilmiştir (Murray ve ark., 2009). Ayrica tatli sorgumda biyoetanol verimi 924 ile $1051 \mathrm{~L} \mathrm{da}^{-1}$ arasında (Gomez ve ark., 2011), 214.3 ila $464.5 \mathrm{~L} \mathrm{da}^{-1}$ arasında (Oktem ve ark., 2018) bildirilmiştir.

Bazı araştırmacılar tarafından farklı etanol verim değerleri rapor edilmiştir. Smith ve Buxton (1993), Iowa'da $600 \mathrm{~L} \mathrm{da}^{-1}$ biyoetanol verimi elde ettiklerini belirtmişlerdir.

Biyoetanol verim değerleri Li (2003) tarafindan 125 ile $562.5 \mathrm{~L} \mathrm{da}^{-1}$ arasında, Teetor ve ark. (2011) tarafindan 81.16 ile $345.85 \mathrm{~L} \mathrm{da}^{-1}$ arasında bildirilmiştir.

Çizelge 7. Özsu oranı, şurup verimi, şeker verimi ve biyoetanol verimine ait varyans analiz değerleri

Table 7. Variance analysis values for plant juice ratio, syrup yield, sugar yield and bioethanol yield characteristics

\begin{tabular}{lccccc}
\hline \multirow{2}{*}{$\begin{array}{l}\text { Varyasyon } \\
\text { kaynağ1 }\end{array}$} & $\begin{array}{c}\text { Serbestlik } \\
\text { derecesi }\end{array}$ & $\begin{array}{c}\text { Özsu oran1 } \\
(\%)\end{array}$ & $\begin{array}{c}\text { Şurup verimi } \\
\left(\mathrm{L} \mathrm{da}^{-1}\right)\end{array}$ & $\begin{array}{c}\text { Şeker verimi } \\
\left(\mathrm{kg} \mathrm{da}^{-1}\right)\end{array}$ & $\begin{array}{c}\text { Biyoetanol } \\
\text { verimi } \\
\left(\mathrm{L} \mathrm{da}^{-1}\right)\end{array}$ \\
\hline Tekerrür & 3 & 0.0311 & 5625.5 & 4576.49 & 2728.02 \\
Çeşit & 15 & $59.27^{* *}$ & $603.7^{* *}$ & $57889.87 * *$ & $18939.56^{* *}$ \\
Hata & 30 & 1.1653 & 1176.8 & 835.7 & 1101.4 \\
Genel & 47 & & & & \\
Varyasyon katsayis1 (\%) & 2.57 & 5.20 & 5.20 & 5.20 \\
\hline
\end{tabular}

**; $\mathrm{P} \leq 0.01$ düzeyinde önemli 
Çizelge 8. Özsu oranı, şurup verimi, şeker verimi ve biyoetanol verimine ait değerler ve oluşan istatistiki gruplar

Table 8. Values and statistical groups for plant juice ratio, syrup yield, sugar yield and bioethanol yield characteristics

\begin{tabular}{lllll}
\hline Çeşitler & $\begin{array}{l}\text { Özsu oranı } \\
(\%)\end{array}$ & $\begin{array}{l}\text { Şurup verimi } \\
\left(\mathrm{L} \mathrm{da}^{-1}\right)\end{array}$ & $\begin{array}{l}\text { Şeker verimi } \\
\left(\mathrm{kg} \mathrm{da}^{-1}\right)\end{array}$ & $\begin{array}{l}\text { Biyoetanol verimi } \\
\left(\mathrm{L} \mathrm{da}^{-1}\right)\end{array}$ \\
\hline 1. Brandes & $44.19 \mathrm{bc}$ & $508.3 \mathrm{fg}$ & $432.1 \mathrm{gh}$ & $230.0 \mathrm{fg}$ \\
2. Corina & $40.96 \mathrm{cde}$ & $586.8 \mathrm{ef}$ & $498.7 \mathrm{efg}$ & $268.9 \mathrm{ef}$ \\
3. Dale & $50.37 \mathrm{a}^{\dagger}$ & $821.1 \mathrm{bc}$ & $698.0 \mathrm{bc}$ & $371.6 \mathrm{bc}$ \\
4. Grassi & $42.14 \mathrm{cde}$ & $641.7 \mathrm{de}$ & $545.4 \mathrm{de}$ & $290.4 \mathrm{de}$ \\
5. M81-E & $43.76 \mathrm{bcd}$ & $931.7 \mathrm{a}$ & $792.0 \mathrm{a}$ & $421.6 \mathrm{a}$ \\
6. P1579753 & $41.25 \mathrm{cde}$ & $541.8 \mathrm{ef}$ & $460.5 \mathrm{efg}$ & $245.2 \mathrm{ef}$ \\
7. Ramada & $40.63 \mathrm{de}$ & $409.0 \mathrm{~g}$ & $347.7 \mathrm{~h}$ & $185.1 \mathrm{~g}$ \\
8. Rio & $30.42 \mathrm{~g}$ & $578.9 \mathrm{ef}$ & $492.1 \mathrm{efg}$ & $262.0 \mathrm{ef}$ \\
9. Roma & $41.61 \mathrm{cde}$ & $563.3 \mathrm{ef}$ & $478.8 \mathrm{efg}$ & $254.9 \mathrm{ef}$ \\
10. Smith & $42.71 \mathrm{bcde}$ & $842.2 \mathrm{ab}$ & $715.8 \mathrm{ab}$ & $381.1 \mathrm{ab}$ \\
11. Theis & $41.70 \mathrm{cde}$ & $927.7 \mathrm{a}$ & $788.6 \mathrm{a}$ & $419.8 \mathrm{a}$ \\
12. Topper 76-I & $45.72 \mathrm{~b}$ & $634.4 \mathrm{de}$ & $539.2 \mathrm{def}$ & $287.1 \mathrm{de}$ \\
13. Topper 76-II & $44.09 \mathrm{bc}$ & $499.1 \mathrm{fg}$ & $424.3 \mathrm{gh}$ & $225.9 \mathrm{fg}$ \\
14. Tracy & $40.32 \mathrm{e}$ & $820.0 \mathrm{bc}$ & $697.0 \mathrm{bc}$ & $371.1 \mathrm{bc}$ \\
15. UNL-Hybrid-3 & $45.98 \mathrm{~b}$ & $732.4 \mathrm{~cd}$ & $624.5 \mathrm{~cd}$ & $331.4 \mathrm{~cd}$ \\
16. Gülşeker & $35.43 \mathrm{f}$ & $522.7 \mathrm{f}$ & $451.3 \mathrm{fg}$ & $236.5 \mathrm{f}$ \\
Ortalama & 41.96 & 660.1 & 561.6 & 294.96 \\
LSD & 3.29 & 104.4 & 87.79 & 101.08 \\
\hline
\end{tabular}

†; Aynı harf ile gösterilen değerler arasında Duncan testine göre $P \leq 0.05$ seviyesinde istatistiksel olarak önemli fark yoktur.

\section{Sonuç}

Çalışmada salkım çıkarma süresi 72.3 ile 102.3 gün, fizyolojik olgunlaşma süresi 128 ile 168 gün, sap verimi 5763.3 ile $14433.2 \mathrm{~kg} \mathrm{da}^{-1}$, tane verimi 82.97 ile $328.18 \mathrm{~kg}$, bin tane ağırlığı 15.41 ile $45.13 \mathrm{~g}$, hektolitre ağırlı̆̆ 51 ile $70 \mathrm{~kg} \mathrm{hL}^{-1}$ arasında bulunmuştur. Biyoyakıt öğesi olarak genotipler arasında sap veriminin en yüksek olduğu genotip Thesis $\left(14433.2 \mathrm{~kg} \mathrm{da}^{-1}\right)$, özsu veriminin en fazla olduğu genotip Dale $\left(6149.14 \mathrm{~L} \mathrm{da}^{-1}\right)$, brix değerinin en fazla olduğu genotip ise Smith (\% 20.4) olarak tespit edilmiştir. Araştırmada, özsu oranı \% 30.42 (Rio) ile \% 50.37 (Dale) arasında, şurup verimi $409.0 \mathrm{~L} \mathrm{da}^{-1}$ (Ramada) ile $931.7 \mathrm{~L} \mathrm{da}^{-1}$ (M81-E) arasında, şeker verimi $347.7 \mathrm{~kg} \mathrm{da}^{-1}$ (Ramada) ile $792.0 \mathrm{~kg} \mathrm{da}^{-1}$ (M81-E) arasında, biyoetanol verimi ise $185.1 \mathrm{~L} \mathrm{da}^{-1}$ (Ramada) ile $421.6 \mathrm{~L} \mathrm{da}^{-1}$ (M81-E) arasında değişmiştir. Sap verimi, özsu verimi, brix, şeker verimi ve biyoetanol verimi gibi biyoyakıt öğeleri göz önüne alındığında Theis, M81-E, Dale, Smith, Tracy ve UNL-Hybrid-3 gibi tatlı sorgum çeşitlerinin diğer çeşitlere göre daha yüksek verimli oldukları gözlenmiştir.

Tatlı sorgum bitkisinin GAP bölgesi ana ürün koşullarında iyi verim düzeylerine ulaştığı, benzer ekolojilerde yetiştirilebileceği ve tatlı sorgum bitkisinin enerji bitkisi olarak kullanım potansiyelinin yüksek olduğu belirlenmiştir.

\section{Kaynaklar}

Acar, R., Akgün, N., 2009. Şeker darısının (Sorgum bicolor (L.) Moench var. saccharatum) yeşil ot verim öğelerine farklı azot dozlarının etkisi. Türkiye 8. Tarla bitkileri kongresi, 1: 637-640, 19-22 Ekim 2009, Hatay.

Almoderes, A., Hadi, M.R., Ranjbar, M., Taheri, R., 2007. The effects of nitrogen treatments, cultivars and harvest stages on stalk yield and sugar content in sweet sorghum. Asian Journal of plant Sciences, 6 (2): 423-426.

Almoderes, A., Hadi, M.R., Ahmadpour, H., 2008. Sorghum stem yield and soluble carbohydrates under different salinity levels. African Journal of Biotechnology, 7 (22): 4051-4055.

Almoderes, A., Goli, M., 2013. Preliminary study on the effect of plant population density and sweet sorghum cultivars on bioethanol production. Biofuels, 4(2): 163-167.

Anonim, 2019. Şanlıurfa Meteoroloji Müdürlüğü 2019 Yılı Bülteni, Şanlıurfa.

Atago, 2021. Atago Co. Ltd., Japonya. https://www.atago.net. 
Avcı, S., İleri, O., Kaya, M.D., 2018. Sorgum'da farklı tohum miktarlarının verim öğeleri ile çimlenme özellikleri üzerine etkileri. Süleyman Demirel Üniversitesi Fen Bilimleri Enstitüsü Dergisi, 22(2): 979-985.

Bunphan, D., Jaisil, P., Sanitchon, J., Knoll, JE., Anderson, WF., 2015. Estimation methods and parameter assessment for ethanol yields from total soluble solids of sweet sorghum. Industrial Crops and Products, 63: 349-356.

Burks, P.S., 2012. Assessing maturity in sweet sorghum hybrids and its role in daily biomass supply. Master of Science, Department of Plant Breeding, Texas University, USA. Pp:240.

Buxton, D.R., Anderson, I.C., Hallam, A., 1999. Performance of sweet sorghum grown continuously, double cropped with winter rye, or in rotation with soybean and maize. Agron. J., (91): 93-101.

Chavan, U.D., Patil, J.V., Shinde, M.S., 2009. An assesment of sweet sorghum cultivars for ethanol production. Sugar Tech., 11 (4): 319-323.

Cole, M.R., Eggleston, G., Petrie, E., Uchimiya, M., Dalley, C., 2017. Cultivar and maturity effects on the quality attributes and ethanol potential of sweet sorghum. Biomass Bioenerg, 9(6): 183-192.

Dalianis, C., Christou, M., Sooter, S., Kyritisis, S., Zafiris, S., Samiotakis, G., 1992. Seventh european conference on biomass for energy and environment. Agriculture and Industry, P.09.09, Florence- Italy, October 5-9.

Dinç, U., Şenol, S., Sayın, M., Kapur, S., Güzel, N., 1988. Güneydoğu Anadolu Bölgesi Toprakları (GAT) I. Harran Ovası, TÜBİTAK, Tarım Ormancılık Araştırma Grubu, Güdümlü Araştırma Projesi Kesin Sonuç Raporu, TAOG, 534, Adana.

Dogget, H., 1988. Sorghum. Published by halow: 2nd edition. Longman scientific and technical tropica agriculture series. International Development Research, 231(4): 243-254.

Frese, L., 1994. Yield potential and utilization possibilities of sugar crops. Field Crop Abstracts, 47: 3469.

Girgin, V.Ç., 2012. Bornova koşullarında ikinci ürün olarak yetiştirilen tatlı sorgum (Sorghum bicolor L.)'da farklı azot dozlarının bazı tarımsal ve teknolojik özelliklere etkisi üzerinde araştırmalar. Yüksek Lisans Tezi, Ege Üniv. Fen Bil. Enst., İzmir.

Gomez F.J.D., Hernandez C.C., Carrillo E.P., Rooney W.L., Saldivar SO., 2011. Evaluation of bioethanol production from five different varieties of sweet and forage sorghums. Industrial Crops and Products, 33(3): 611616.

Grassi, G., 2001. Sweet sorghum: One of the best world food-feed-energy crop. http://web.etaflorence.it/uploads/media/LAMNET_sweet_sorghum.pdf.

Guiying, L., Weibin, G., Hicks, A., Chapman., K.R., 2003. A training manual for sweet sorghum. Development of sweet sorghum for grain, sugar, feed, fiber and value-added By-products, in the arid, Saline- alkaline regions of China. FAO-TCP/CPR/0066.http://ecoport.org/ep?SearchType=earticleView\&earticleId $=172 \&$ page $=2$

Horton, D.S., 2011. Evaluation of sweet sorghum cultivars as a potential ethanol crop in Mississippi. MS Thesis. Department of Plant and Soil Sciences, Mississippi State University, USA.

Jia, F., Chawhuaymak, J., Riley, MR., Zimmt, W., Ogden, KL., 2013. Efficient extraction method to collect sugar from sweet sorghum. J Biol Eng.7:1. doi: 10.1186/1754-1611-7-1.

Koppen, S., Reinhardt, G., Gartner, S., 2009. Assesment of energy and greenhouse gas invertories of sweet sorghum for first and second generation bioethanol. enviroment and natural resources management series, 30, FAO, Rome.

Li, D., 2003. Ethanol fuel from sweet sorghum desiderates development. J. Agric. Sci. Technol., 4: 48-51.

Murray, SC., Rooney, WL., Hamblin, MT., Mitchell, SE., Kresovich S., 2009. Sweet sorghum genetic diversity and association mapping for brix and height. Plant Genome, 2(1): 48-62.

Mülayyim, M., Özköse, A., Işık, Ş., 2009. Konya koşullarında sorgum x sudanotu melezi çeşitlerinde verim ve bazı tarımsal özelliklerin belirlenmesi. Türkiye VIII. Tarla Bitkileri Kongresi, 17 Kasım, Hatay, s.627-630.

Naoyuki, T., Yusuke, G., 2004. Cultivation of sweet sorghum (Sorghum bicolor (L.) Moench) and determination of its harvest time to make use as the raw material for fermentation, practiced during rainy season in dry land of Indonesia. Plant Production Science, 7: 442-448.

Reddy, B.V.S., Ramesh, S., Reddy, P.S., Ramaiah, B., Salımath, P.M., Kachapur, R., 2005. Sweet sorghum-a potential alternate raw material for bio-ethanol and bioenergy, international sorghum and millets newsletter, 46 : $79-86$.

Rutto, L.K., Xu, Y., Brandt, M., S., Kering, M.K., 2013. Juice ethanol and grain yield potential of five sweet sorghum (Sorghum bicolor (L.) Moench) cultivars. J. Sustain. Bioenerg., 3: 113-118.

Samarth, AG., More DR., Hashmi I., 2018. Studies on physico-chemical properties and nutritional profile of sweet sorghum. International Journal of Chemical Studies, 6(2): 2826-2828.

Smith, GA., Buxton, DR., 1993. Temperate zone sweet sorghum ethanol production potential. Bioresource Tech., 43(1): 71-75. 
Subramanian, S.K., 2013. Agronomical, physiological and biochemical approaches to characterize sweet sorghum genotypes for biofuel production. PhD Thesis. p.205, Department of Agronomy College of Agriculture. Kansas State University, Manhattan, Kansas.

Teetor, VH., Duclos, DV., Wittenberg, ET., Young, KM., Chawhuaymak, J., Riley, MR., Ray, DT., 2011. Effects of planting date on sugar and ethanol yield of sweet sorghum grown in Arizona. Industrial Crops and Products, 34(2): 1293-1300.

Tsuchihashi, N., Goto, Y., 2004. Cultivation of sweet sorghum (Sorghum bicolor (L.) Moench) and determination of its harvest time to make use as the raw material for fermantation, practiced during rainy season in dry land of Indonesia. Plant Proc. Sci., 7(4): 442-448.

Öktem, A., Öktem AG., Avc1oglu, E., 2018. Determination of yield and biofuel potential of some early sweet sorghum (Sorghum bicolor var. saccharatum (L.) Mohlenbr.) Genotypes. IX International Scientific Agriculture Symposium-Agrosym 2018, Jahorina, 04-07 October, Bosnia and Herzegovina. Pp.753-758.

Öktem, A., Öktem, AG., 2018. Usage of energy plants as a biofuel source. Current Academic Studies in Agricultural Science. Ed. Nurhan Keskin, Ivpe, Cetinje- Montenegro. Pp.333-354. ISBN: 978-9940-540-48-7.

Yurtsever, N., 1984. Deneysel İstatistik Metotları. Toprak ve Gübre Araştırma Enstitüsü Genel Yayın No:121, Ankara.

Zhao, Y.L.I., Dolat, A., Steinberger, Y., Wanga, X., Osman, A., Xie, G.H., 2009. Biomass yield and changes in chemical composition of sweet sorghum cultivars grown for biofuel. Field crops research, 111: 55-64. 